Supplementary Materials

\title{
Chemoselective Coupling of $\mathrm{CS}_{2}$ and Epoxides for Producing Poly(thioether)s and COS via Oxygen/Sulfur Atom Exchange
}

Cheng-Jian Zhang and Xing-Hong Zhang*

MOE Key Laboratory of Macromolecular Synthesis and Functionalization, Department of Polymer Science and Engineering, Zhejiang University, Hangzhou 310027, China. 


\section{Table of Contents}

Fig. S1 ${ }^{1} \mathrm{H}$ NMR in $\mathrm{CDCl}_{3}$ of (a) crude products in Table 1, entry 1 and (b) the separated TTPC .4

Fig. S2 (a) GC-TOF-MS and (b) GC-MS of the released gas dissolved in THF...........5

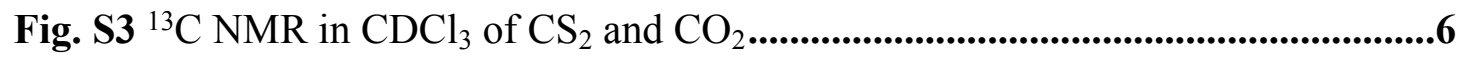

Fig. $\mathbf{S 4}{ }^{1} \mathrm{H}$ NMR in $\mathrm{CDCl}_{3}$ of crude products in (a) table S1, entry 2, (b) Table 1, entry 2 and (c) Table 1 , entry 5

Fig. S5 DSC curves of the generated poly(thioether)s in entries 1, 6, 7, 8, 9 and 10 in

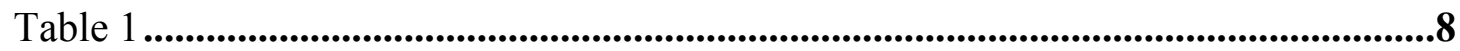

Fig. S6 (a) ${ }^{1} \mathrm{H} \mathrm{NMR}$ and (b) ${ }^{13} \mathrm{C} \mathrm{NMR}$ in $\mathrm{CDCl}_{3}$ of purified products in Table 1, entry

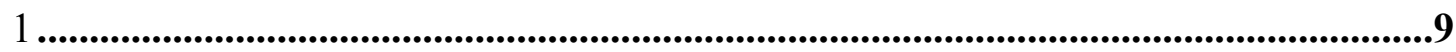

Fig. S7 (a) ${ }^{1} \mathrm{H}$ NMR and (b) ${ }^{13} \mathrm{C}$ NMR in $\mathrm{CDCl}_{3}$ of purified products in table S1, entry 1

Fig. S8 (a) ${ }^{1} \mathrm{H}$ NMR of the crude products, (b) ${ }^{1} \mathrm{H}$ NMR and (c) ${ }^{13} \mathrm{C}$ NMR of the purified products in $\mathrm{CDCl}_{3}$ in Table 1 , entry 6

Fig. S9 (a) ${ }^{1} \mathrm{H}$ NMR of the crude products, (b) ${ }^{1} \mathrm{H}$ and (c) ${ }^{13} \mathrm{C}$ NMR of the purified products in $\mathrm{CDCl}_{3}$ in Table 1, entry 7

Fig. S10 (a) ${ }^{1} \mathrm{H}$ NMR of the crude products, (b) ${ }^{1} \mathrm{H}$ and (c) ${ }^{13} \mathrm{C}$ NMR of the purified products in $\mathrm{CDCl}_{3}$ in Table 1 , entry 8 .13

Fig. S11 (a) ${ }^{1} \mathrm{H}$ NMR of the crude products, (b) ${ }^{1} \mathrm{H}$ and (c) ${ }^{13} \mathrm{C}$ NMR of the purified products in $\mathrm{CDCl}_{3}$ in Table 1 , entry 9

Fig. S12 (a) ${ }^{1} \mathrm{H}$ NMR of the crude products, (b) ${ }^{1} \mathrm{H}$ and (c) ${ }^{13} \mathrm{C}$ NMR of the purified products in $\mathrm{CDCl}_{3}$ in Table 1 , entry 10 15

Fig. S13 MALDI-TOF MS spectrum of PPS oligomers after click reaction with maleimide .16

Fig. S14 (a) ${ }^{1} \mathrm{H}$ and (b) ${ }^{13} \mathrm{C} \mathrm{NMR}$ in $\mathrm{CDCl}_{3}$ of the crude products in the coupling reaction of $\mathrm{CS}_{2}$ and $\mathrm{PO}$ at $120{ }^{\circ} \mathrm{C}$.

Fig. S15 GC-MS of the crude products in the coupling reaction of $\mathrm{CS}_{2}$ and $\mathrm{PO}$ at 120 
${ }^{\circ} \mathrm{C}$

Fig. S16 The picture of DBU (0.15 mmol), $\mathrm{CS}_{2}(0.15 \mathrm{mmol})$, and mixture of DBU (0.15

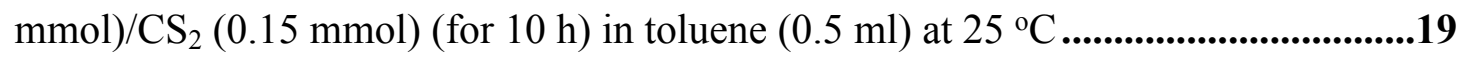

Fig. $\mathbf{S 1 7}{ }^{1} \mathrm{H}$ NMR in $\mathrm{CDCl}_{3}$ of (a) DBU and (b) the precipitate in fig. S16 .................20

Fig. $\mathbf{S 1 8}{ }^{1} \mathrm{H}$ NMR spectra in $\mathrm{CDCl}_{3}$ of the crude-products in table $\mathrm{S} 2$........................21

Fig. S19 (a) ${ }^{1} \mathrm{H}$ NMR and (b) ${ }^{13} \mathrm{C}$ NMR of the purified products in $\mathrm{CDCl}_{3}$ in table $\mathrm{S} 2$, entry 3 .....

Fig. S20 (a) ${ }^{1} \mathrm{H}$ NMR and (b) ${ }^{13} \mathrm{C}$ NMR of the purified products in $\mathrm{CDCl}_{3}$ in table $\mathrm{S} 2$, entry 4 . .23

Fig. S21 GPC curves of the generated poly(thioether)s in entries 1, 6, 7, 8, 9 and 10 in Table 1

Table S1. Coupling Reaction of PO with $\mathrm{CS}_{2}$ using DBU .25

Table S2. Coupling Reaction of propylene sulfide with $\mathrm{CS}_{2}$ using DBU .26 


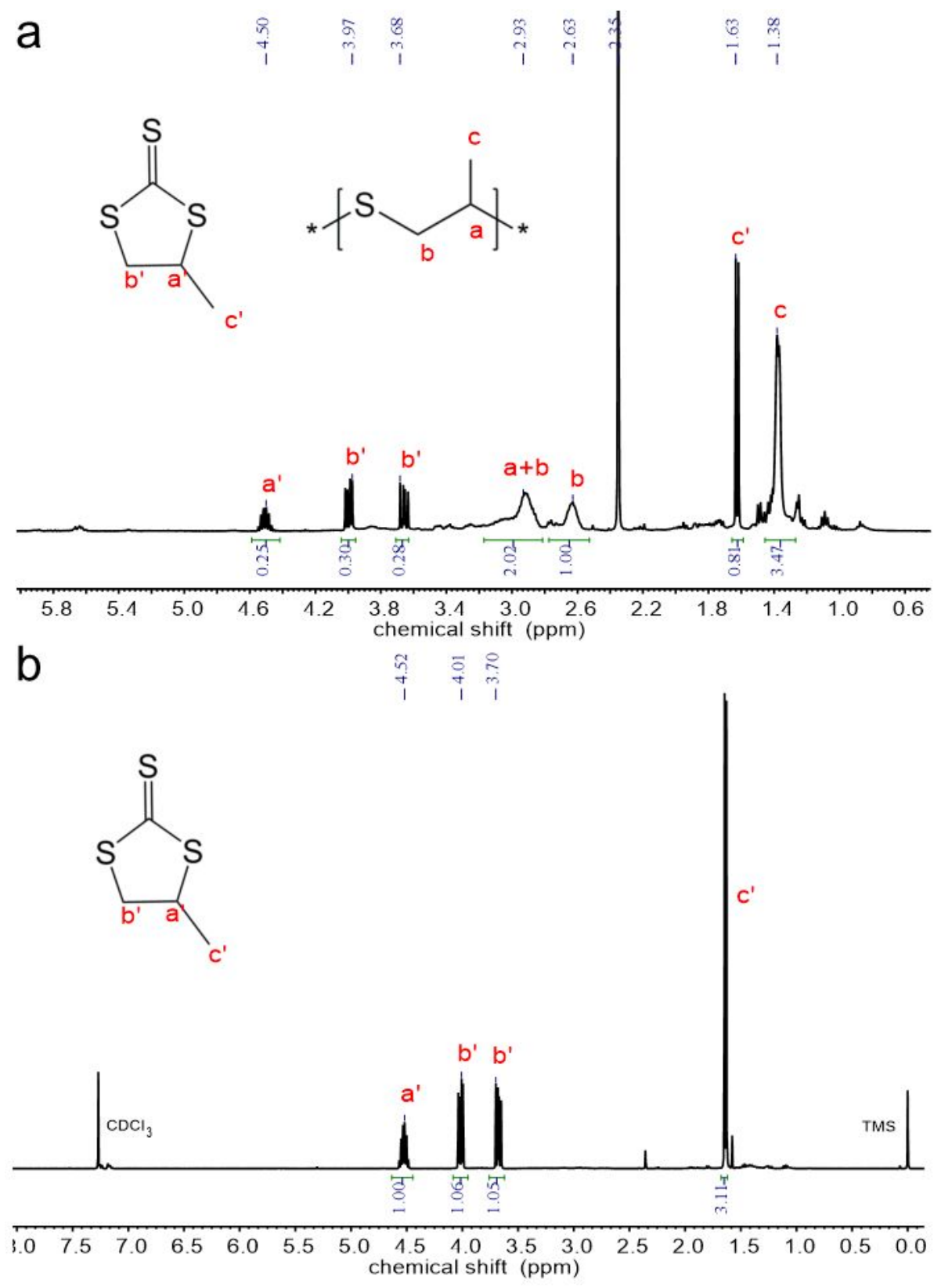

Fig. S1 ${ }^{1} \mathrm{H}$ NMR spectra in $\mathrm{CDCl}_{3}$ of (a) crude products in Table 1, entry 1 and (b) the separated TTPC (The crude products were firstly eluted from a silica-gel column by $\mathrm{CH}_{2} \mathrm{Cl}_{2}$ to remove DBU and concentrated. Then excess diethyl ether was added, and removed insoluble part via filtration. Finally, diethyl ether was removed under decompression conditions, and separated TTPC was obtained). 
$\boldsymbol{a}$

Elemental Composition Report

Page 1

Tolerance $=1.5 \mathrm{mDa} / \mathrm{DBE}: \min =-1.5, \max =50.0$

Element prediction: Off

Monoisotopic Mass, Odd and Even Electron Ions

9 formula(e) evaluated with 1 results within limits (up to 70 closest results for each mass)

Elements Used:

$\begin{array}{llll}\text { C: } 0-50 & \mathrm{H}: 0-100 & \text { O: } 0-6 & \text { S: } 0-2\end{array}$

ZCJ0708-2 397 (3.971)

TOF MS EI+

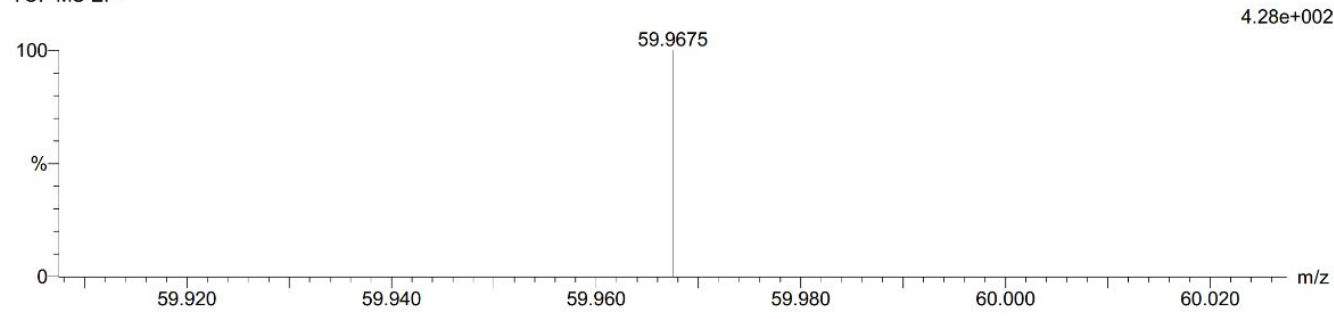

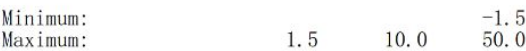

Mass Calc. Mass mDa PPM DBE i-FIT Formula

$\begin{array}{lllllllll}59.9675 & 59.9670 & 0.5 & 8.3 & 2.0 & 5546123.5 & \text { C } & 0 & \text { S }\end{array}$

b
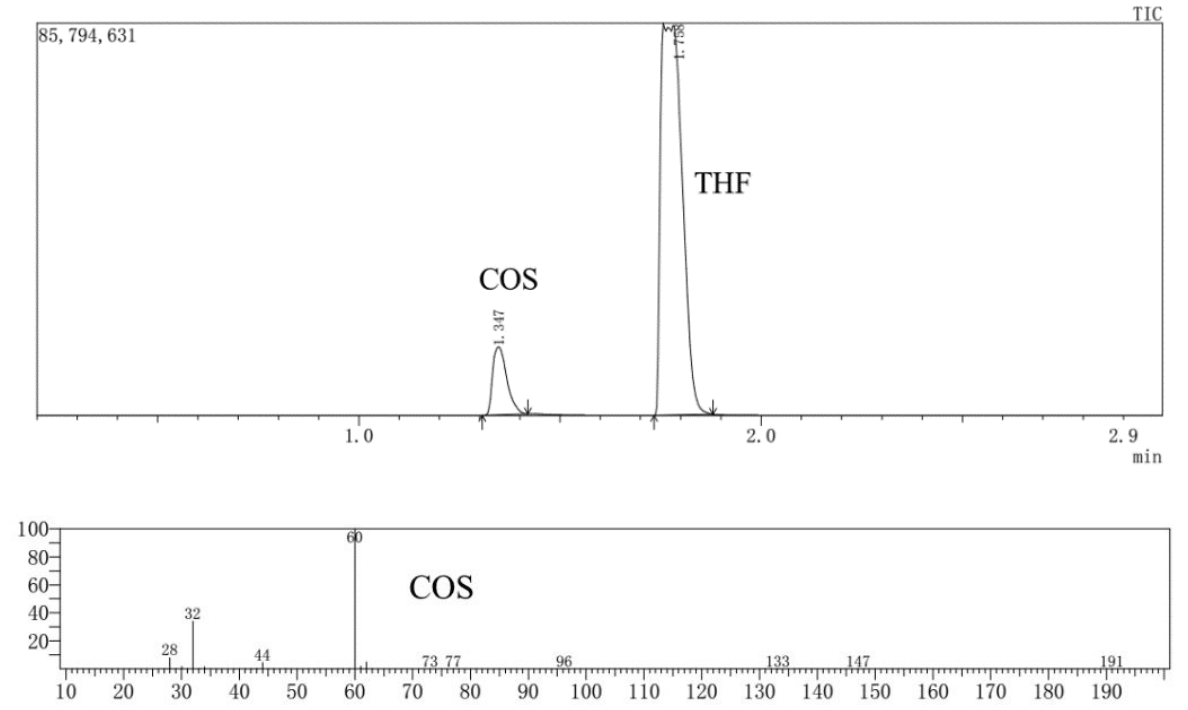

Fig. S2 (a) GC-TOF-MS and (b) GC-MS of the released gas dissolved in THF. 


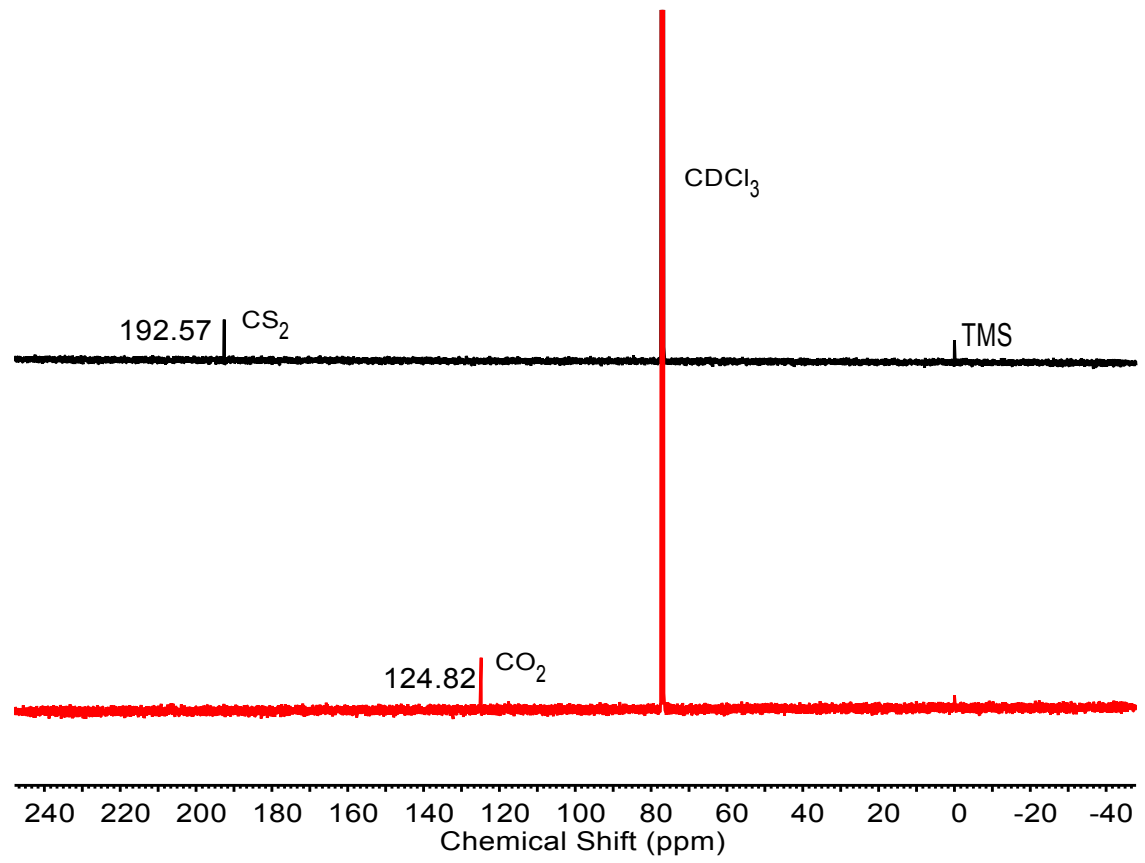

Fig. $\mathrm{S3}^{13} \mathrm{C}$ NMR spectra in $\mathrm{CDCl}_{3}$ of $\mathrm{CS}_{2}$ and $\mathrm{CO}_{2}$. 


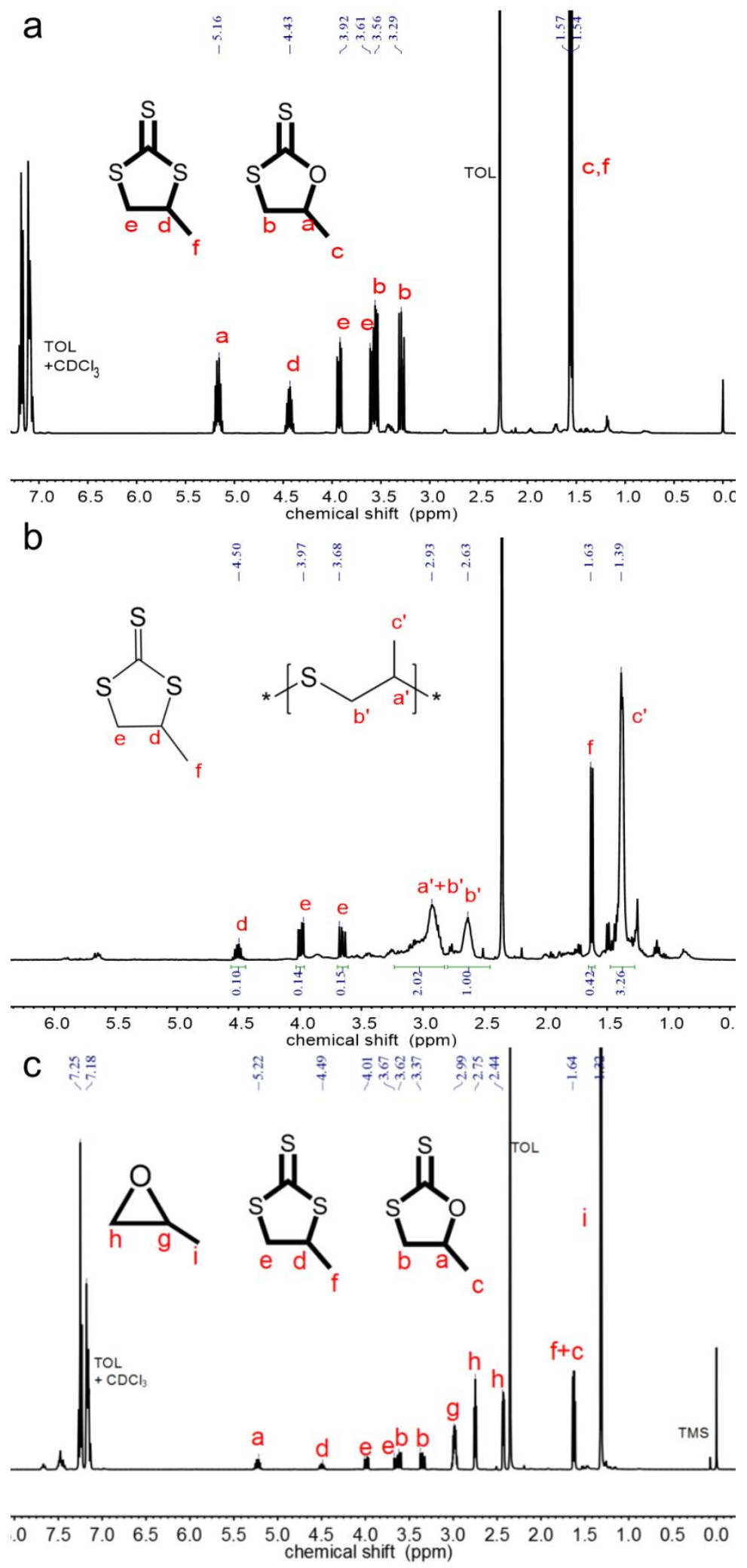

Fig. S4 ${ }^{1} \mathrm{H}$ NMR spectra in $\mathrm{CDCl}_{3}$ of crude products in (a) table S1, entry 2, (b) Table 1, entry 2 and (c) Table 1, entry 5. 


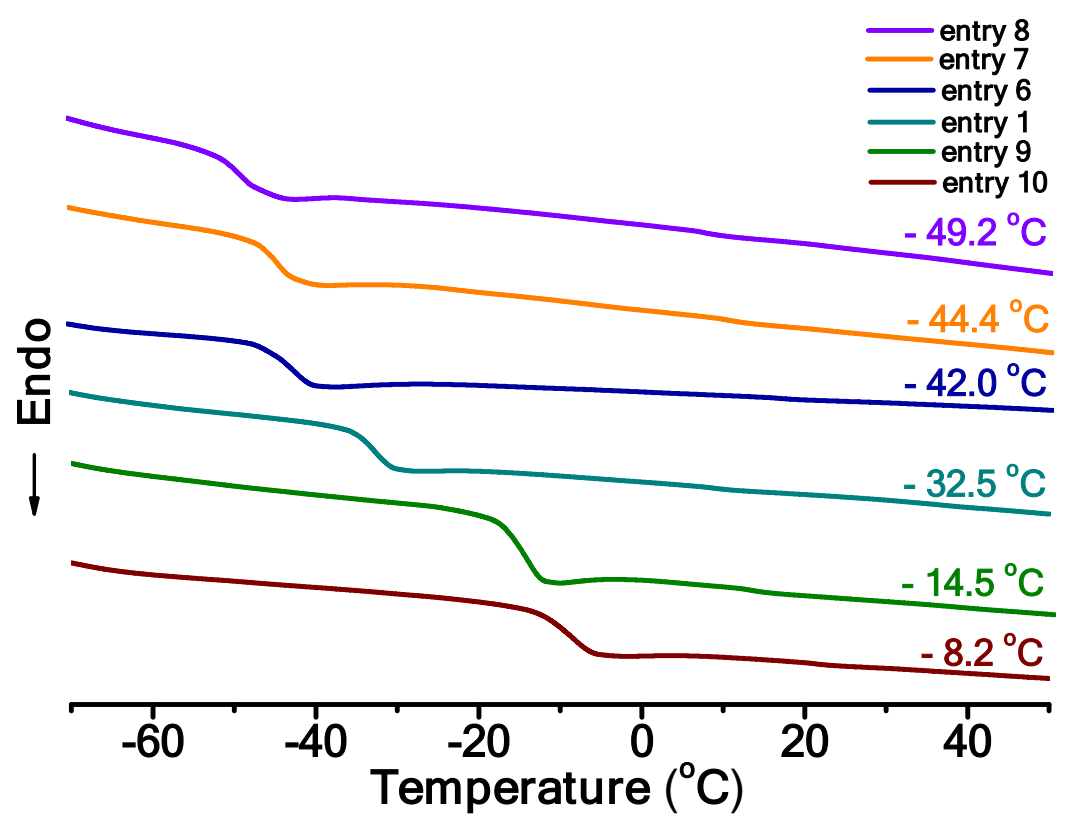

Fig. S5 DSC curves of the generated poly(thioether)s in entries 1, 6, 7, 8, 9 and 10 in Table 1. 
a

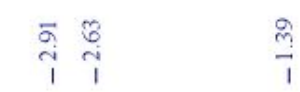<smiles>CC(CSC(C)(C)C)C(C)(C)C</smiles>
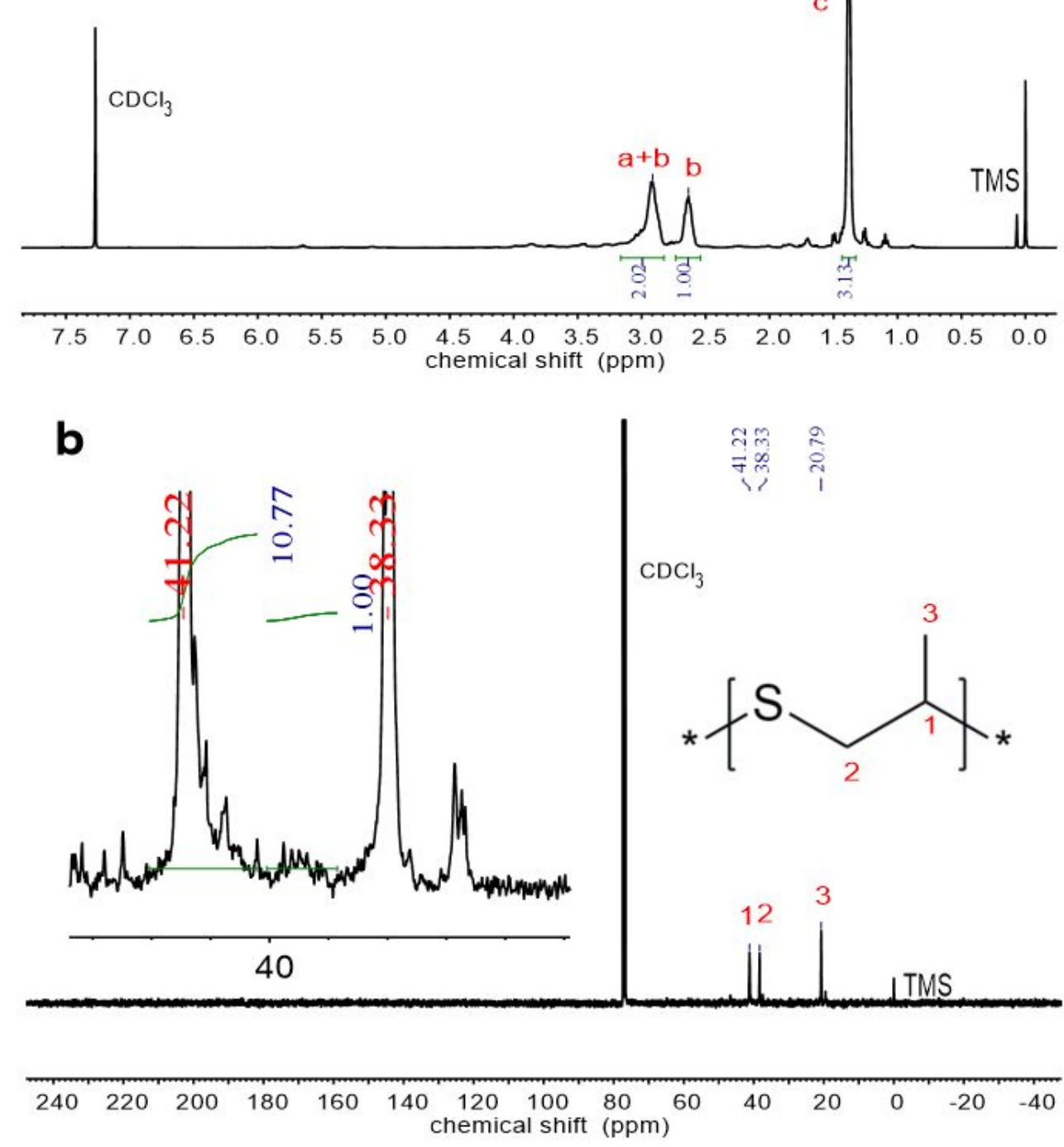

Fig. S6 (a) ${ }^{1} \mathrm{H}$ NMR and (b) ${ }^{13} \mathrm{C}$ NMR spectra in $\mathrm{CDCl}_{3}$ of purified products in Table 1, entry 1. 
a
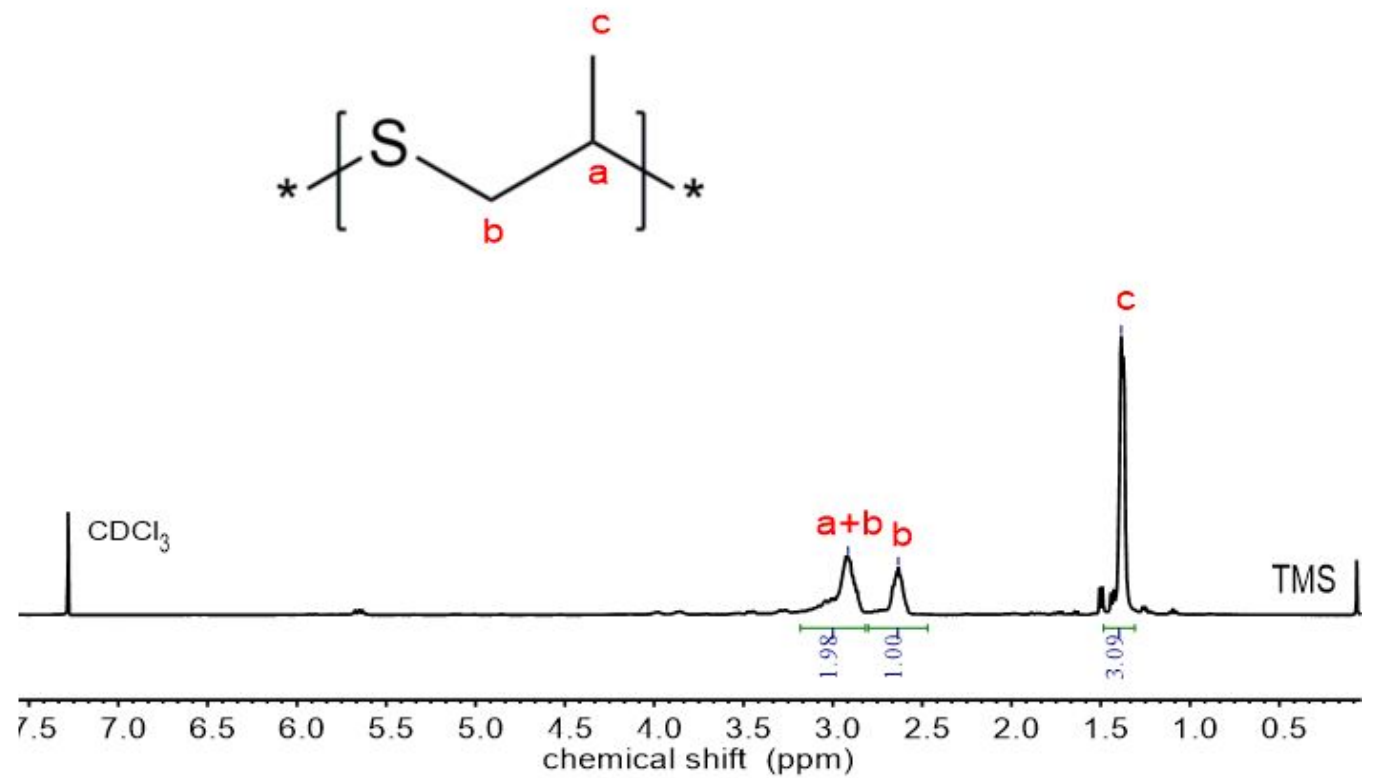

b

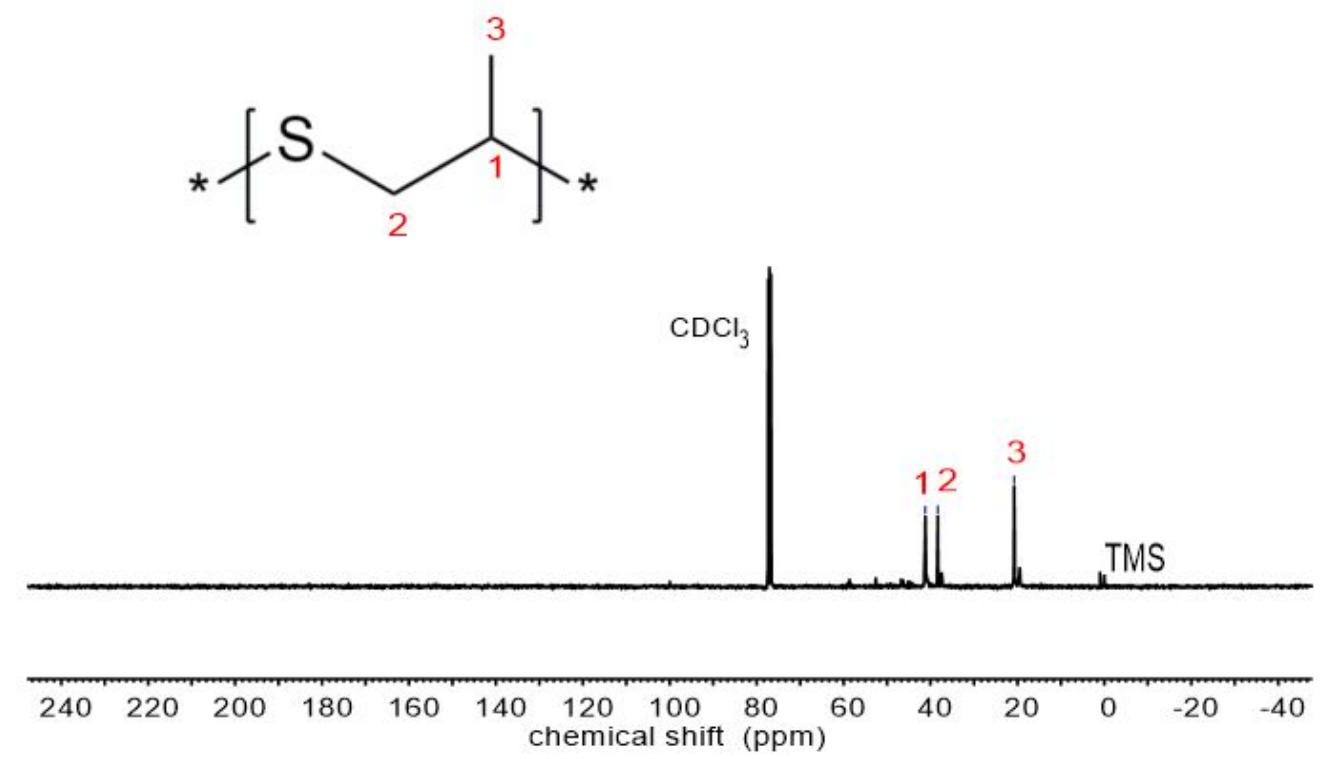

Fig. S7 (a) ${ }^{1} \mathrm{H}$ NMR and (b) ${ }^{13} \mathrm{C}$ NMR spectra in $\mathrm{CDCl}_{3}$ of purified products in table S1, entry 1. 


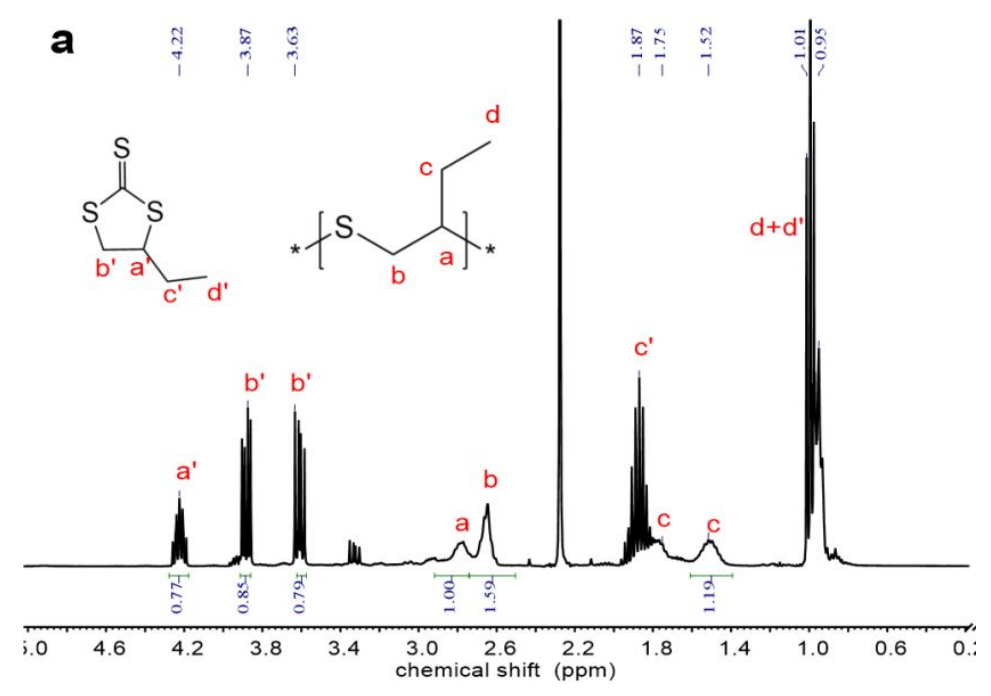

b
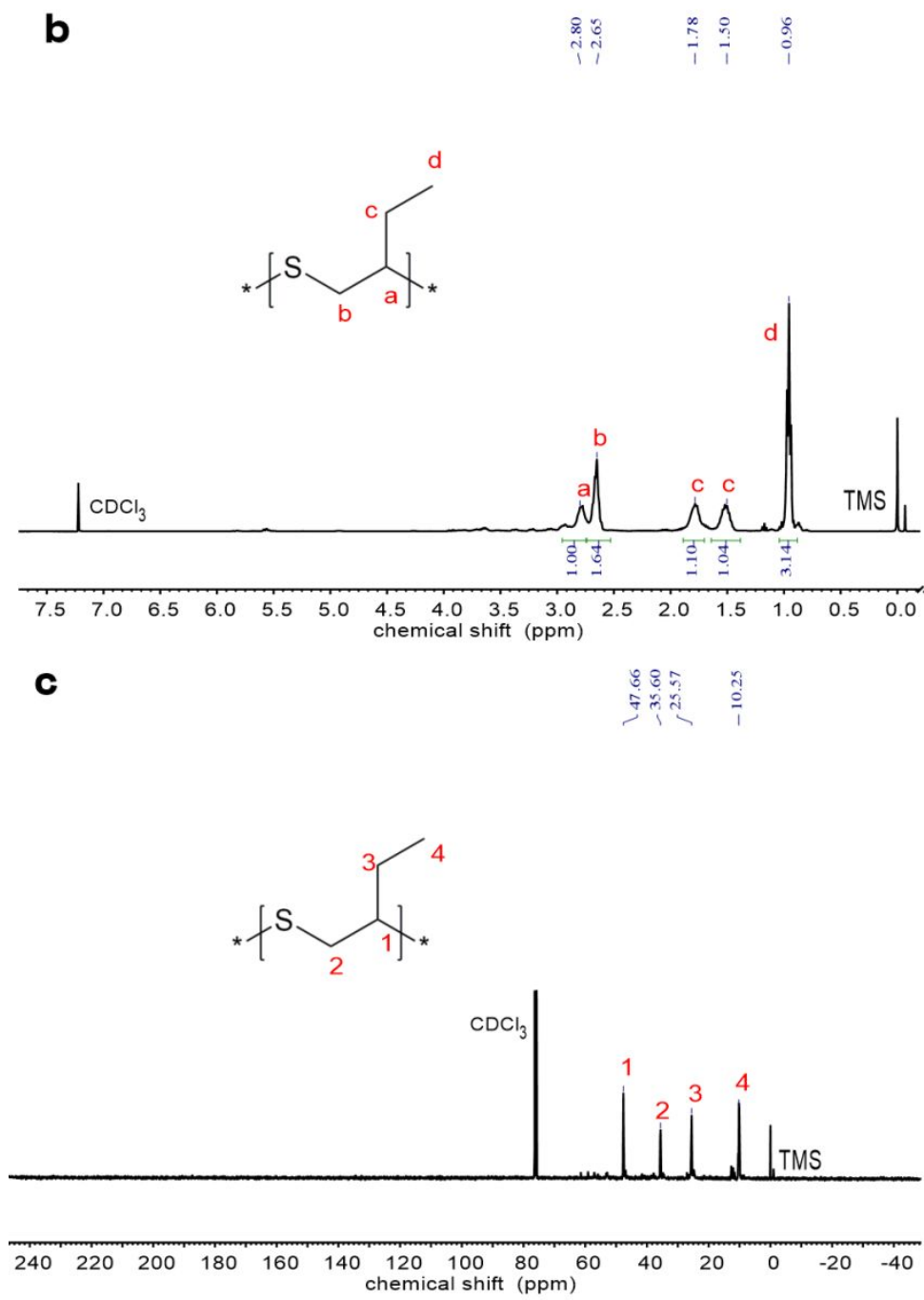

Fig. S8 (a) ${ }^{1} \mathrm{H}$ NMR spectrum of the crude products, (b) ${ }^{1} \mathrm{H}$ NMR and (c)

${ }^{13} \mathrm{C}$ NMR spectra of the purified products in $\mathrm{CDCl}_{3}$ in Table 1 , entry 6. 

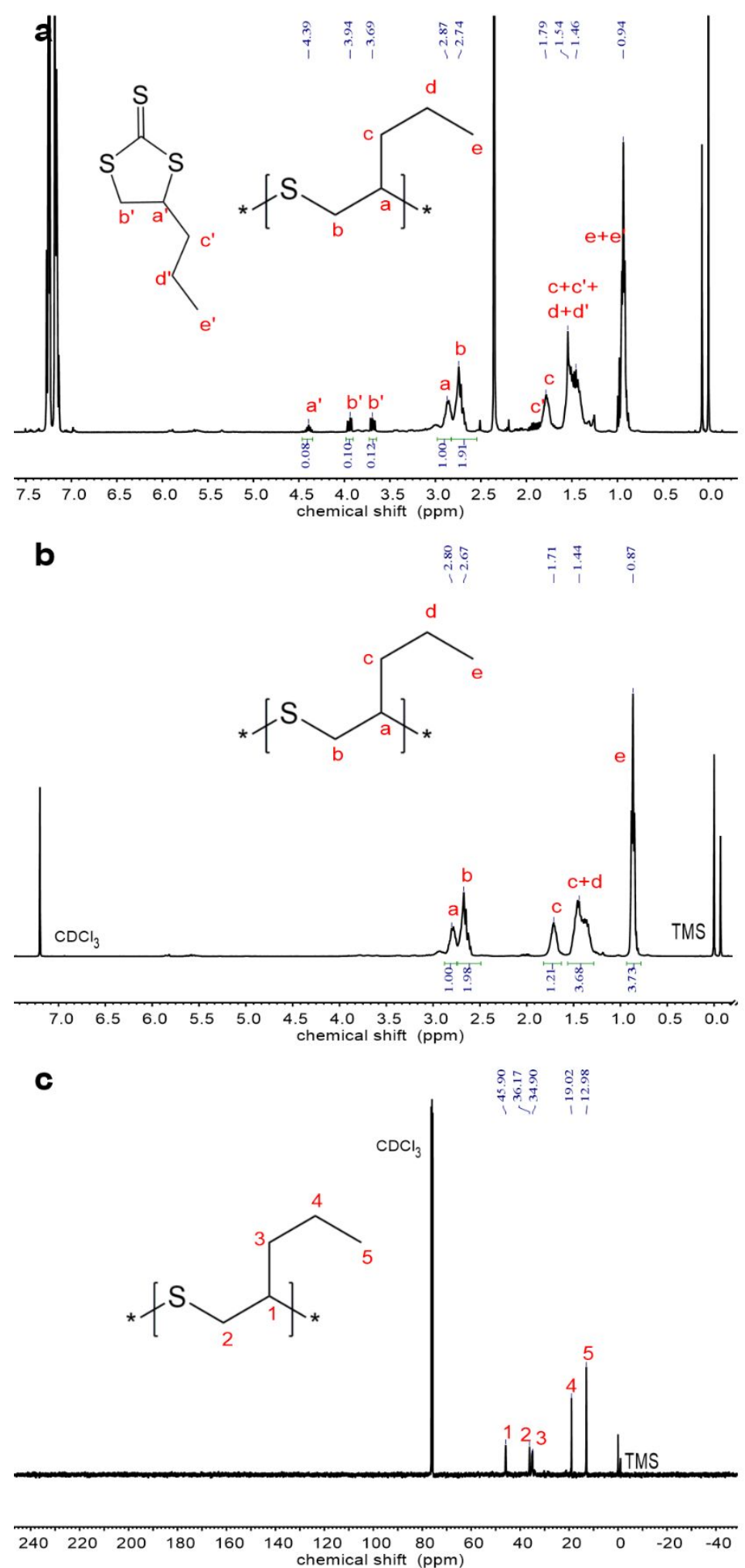

Fig. S9 (a) ${ }^{1} \mathrm{H}$ NMR spectrum of the crude products, (b) ${ }^{1} \mathrm{H}$ and (c) ${ }^{13} \mathrm{C}$ NMR spectra of the purified products in $\mathrm{CDCl}_{3}$ in Table 1, entry 7. 

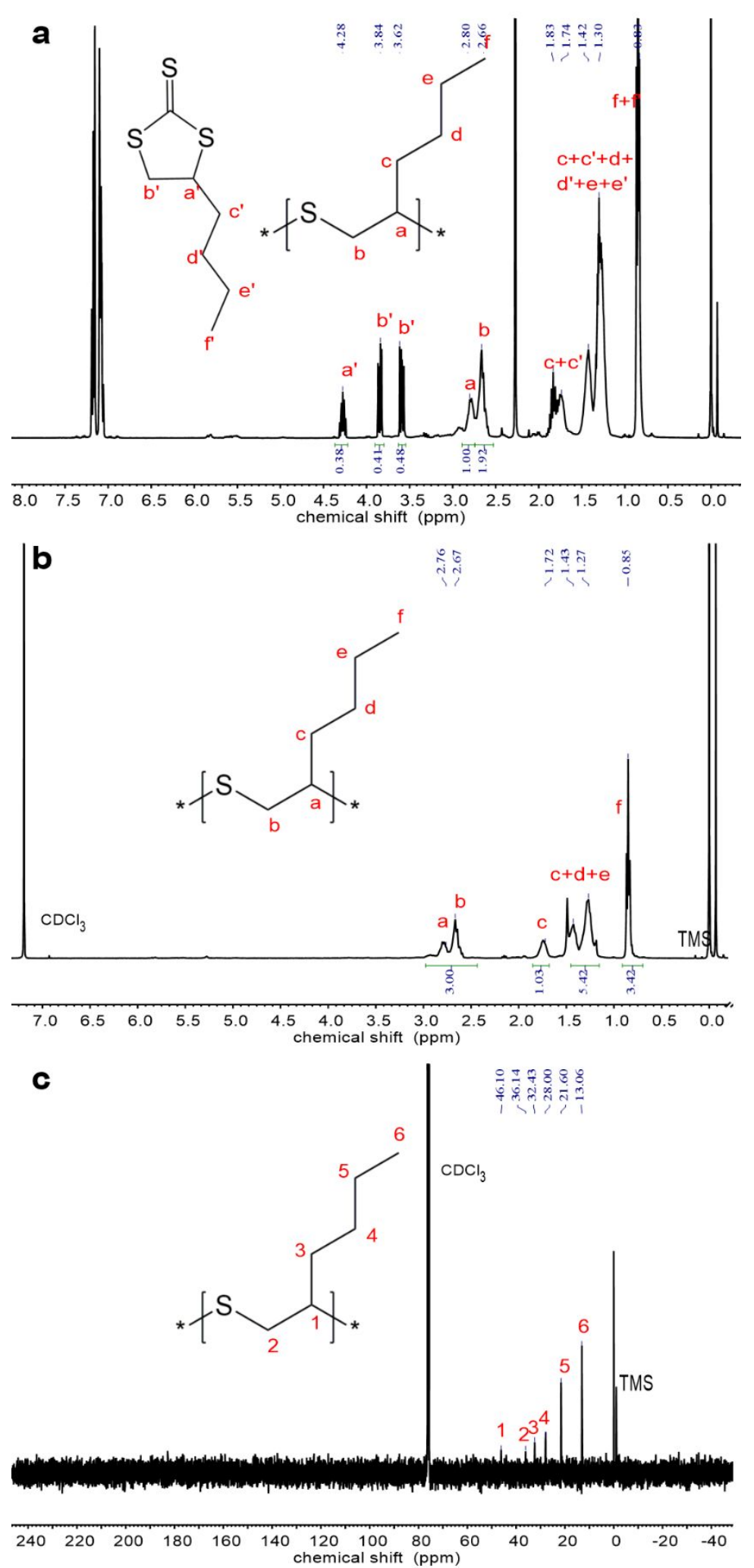

Fig. S10 (a) ${ }^{1} \mathrm{H}$ NMR spectrum of the crude products, (b) ${ }^{1} \mathrm{H}$ and (c) ${ }^{13} \mathrm{C}$ NMR spectra of the purified products in $\mathrm{CDCl}_{3}$ in Table 1 , entry 8 . 


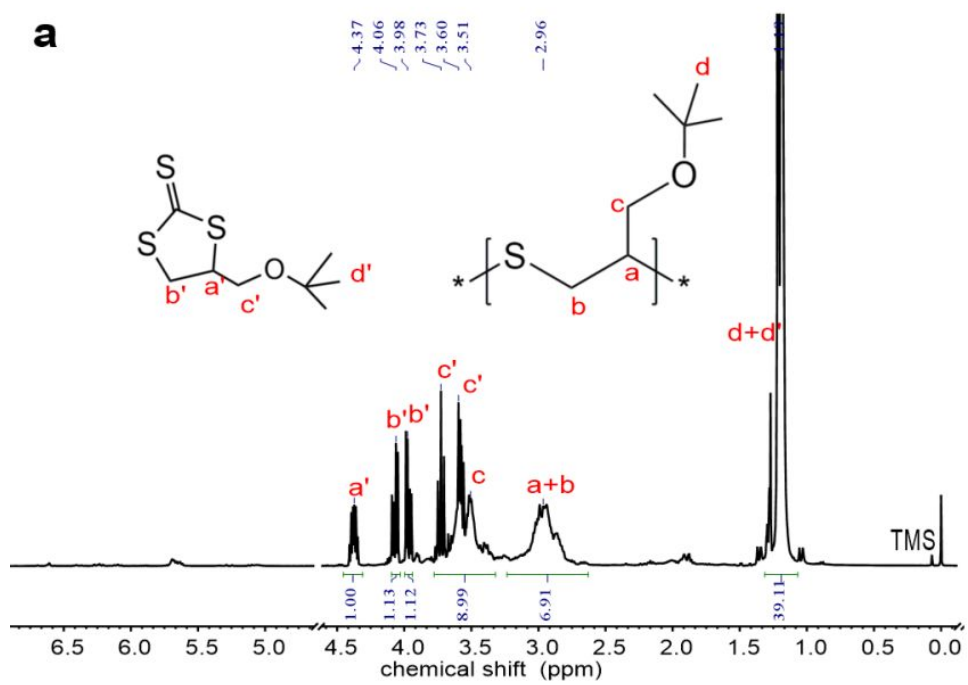

b
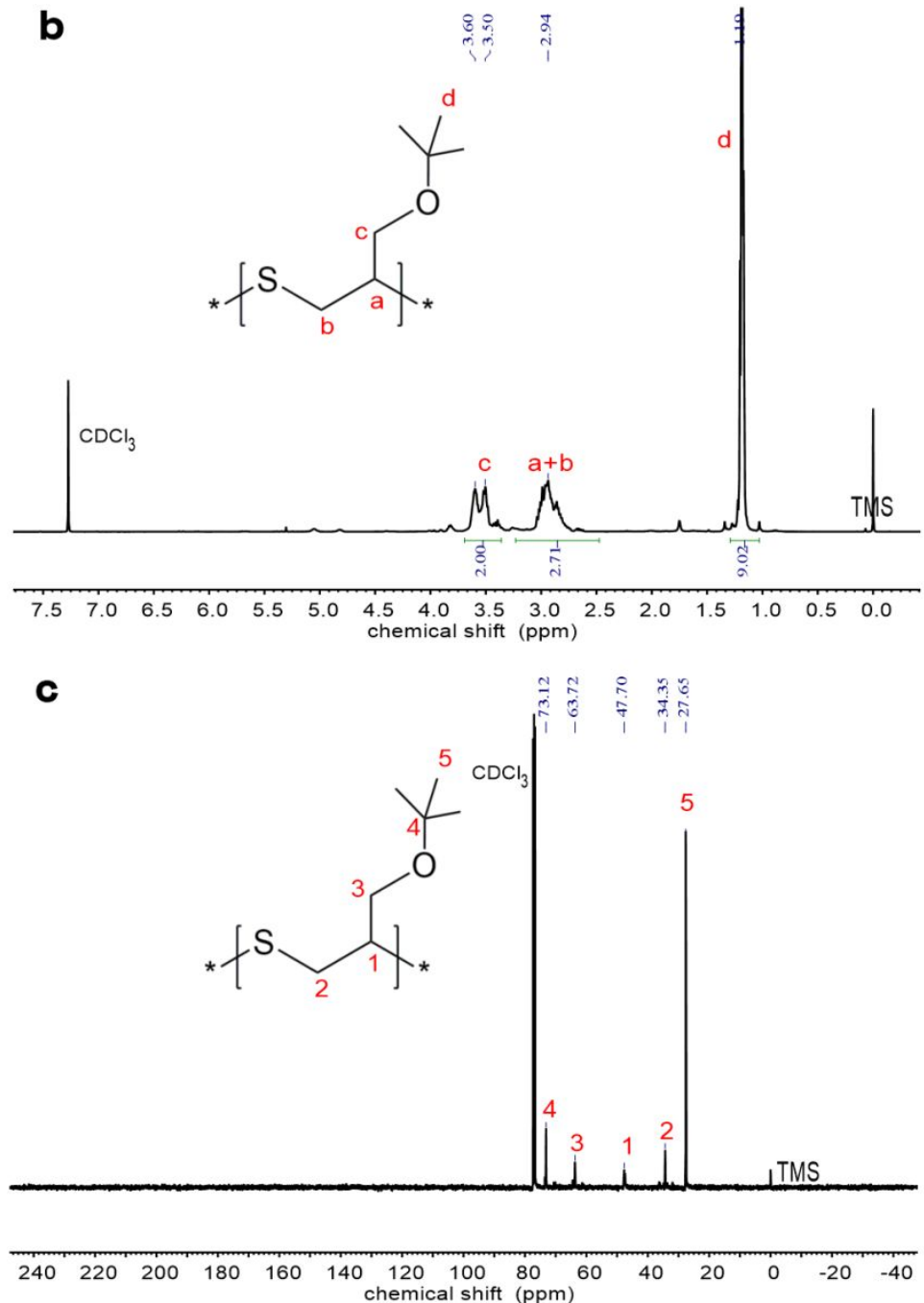

Fig. S11 (a) ${ }^{1} \mathrm{H}$ NMR spectrum of the crude products, (b) ${ }^{1} \mathrm{H}$ and (c) ${ }^{13} \mathrm{C}$ NMR spectra of the purified products in $\mathrm{CDCl}_{3}$ in Table 1, entry 9. 


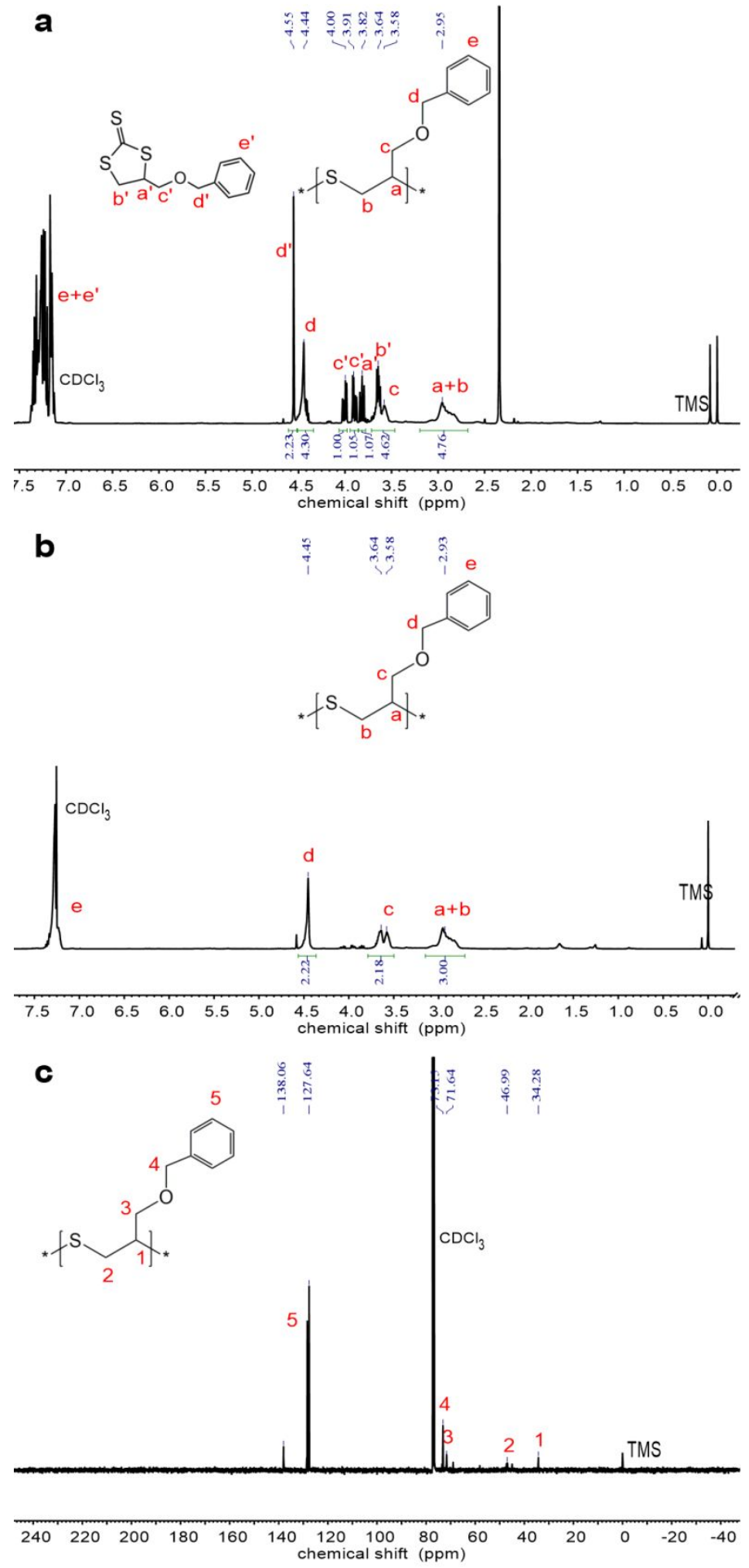

Fig. S12 (a) ${ }^{1} \mathrm{H}$ NMR spectrum of the crude products, (b) ${ }^{1} \mathrm{H}$ and (c) ${ }^{13} \mathrm{C}$ NMR spectra of the purified products in $\mathrm{CDCl}_{3}$ in Table 1, entry 10. 


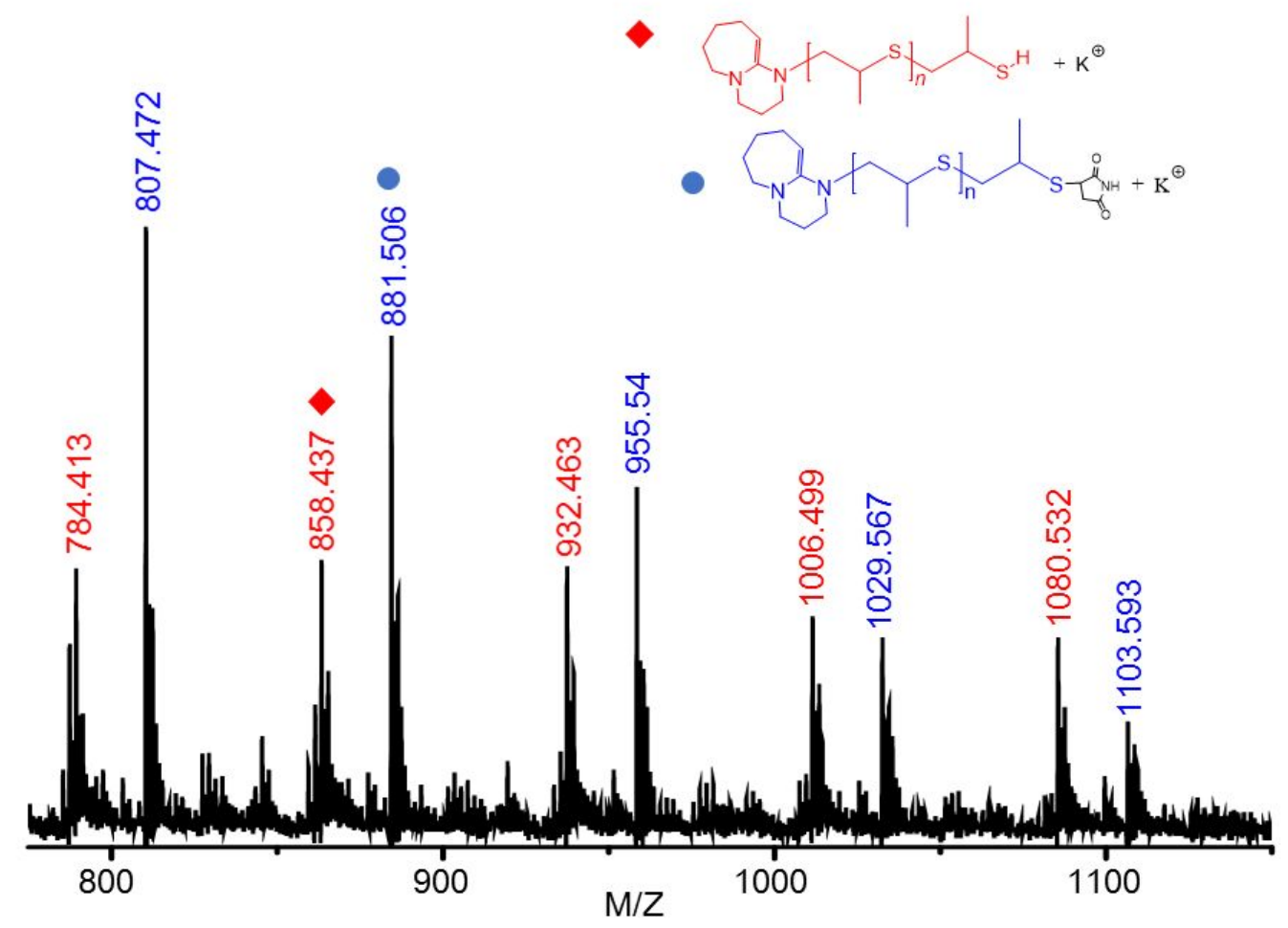

Fig. S13 MALDI-TOF MS of PPS oligomers after click reaction with maleimide. Poly $\left(\mathrm{C}_{3} \mathrm{H}_{6} \mathrm{~S}\right)_{7}=\left[\mathrm{DBU}+\left(\mathrm{C}_{3} \mathrm{H}_{6} \mathrm{~S}\right)_{9}+\mathrm{H}+\mathrm{K}^{+}, \mathrm{m} / \mathrm{z}=859.63\right]$ or $\left[\mathrm{DBU}+\left(\mathrm{C}_{3} \mathrm{H}_{6} \mathrm{~S}\right)_{9}+\mathrm{H}+\mathrm{C}_{4} \mathrm{H}_{3} \mathrm{NO}_{2}+\mathrm{K}^{+}, \mathrm{m} / \mathrm{z}=956.70\right]$ 

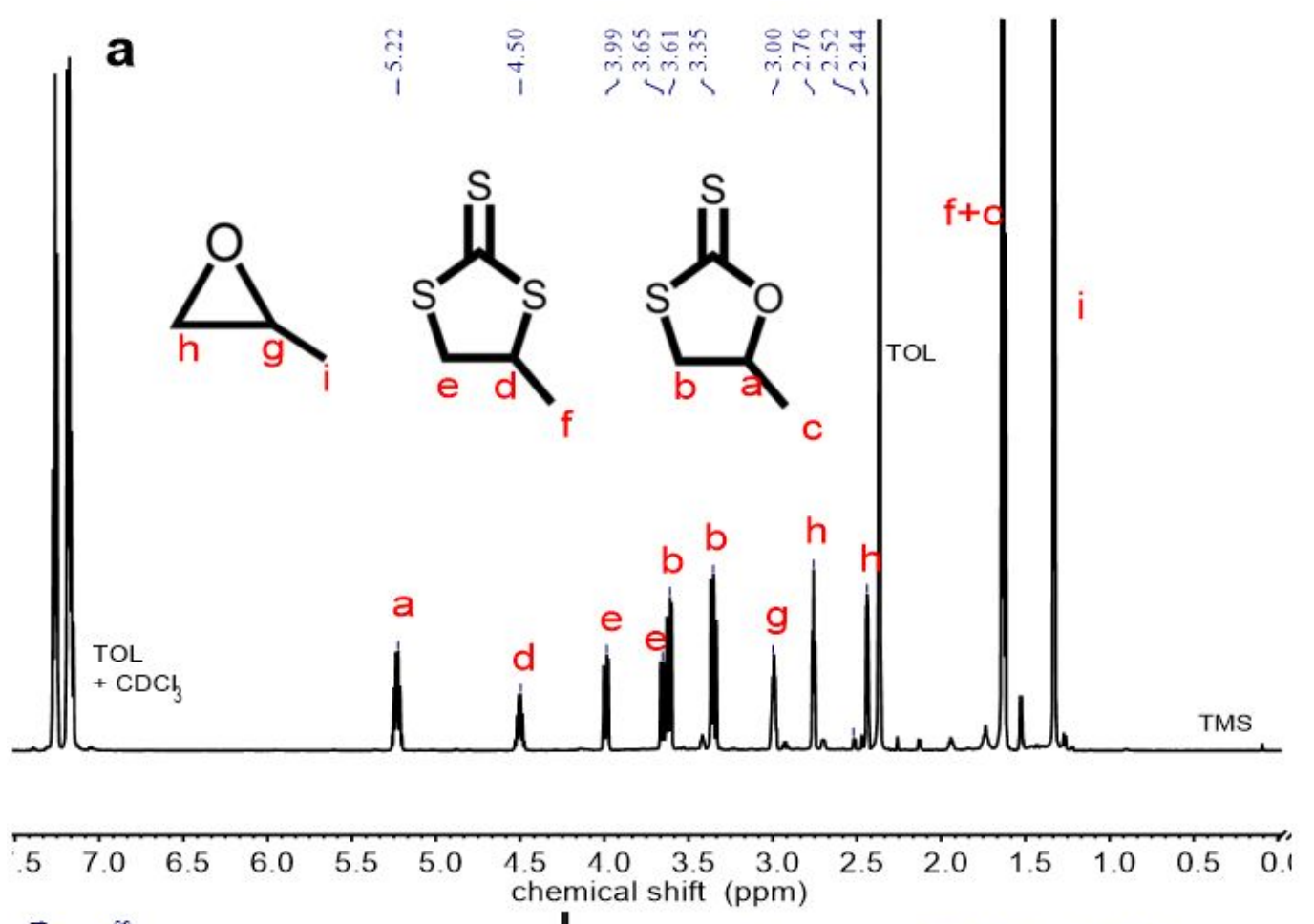

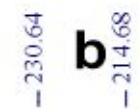
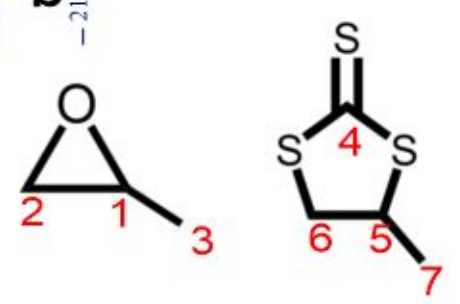

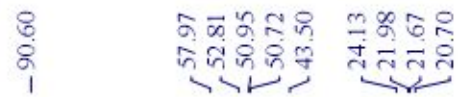
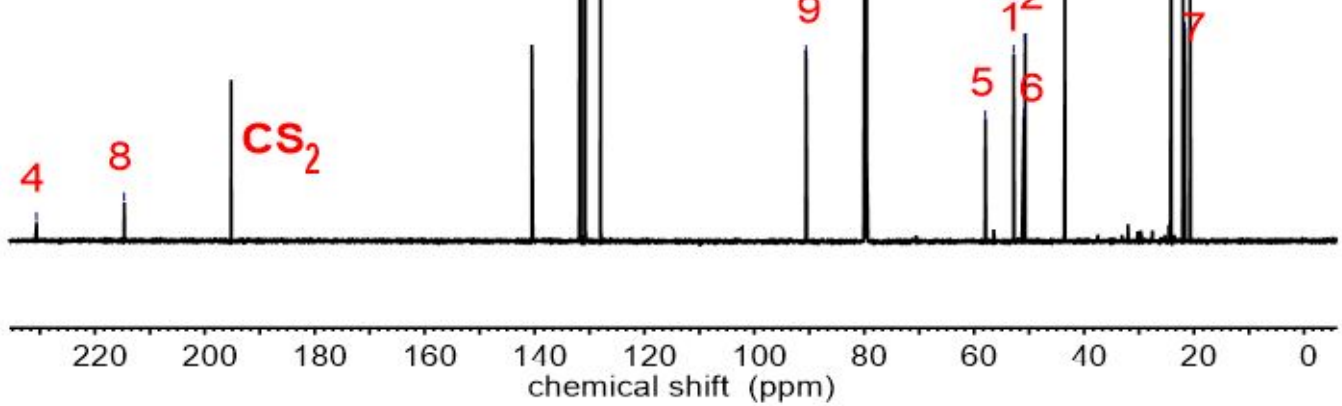

Fig. $\mathbf{S 1 4}$ (a) ${ }^{1} \mathrm{H}$ and (b) ${ }^{13} \mathrm{C}$ NMR spectra in $\mathrm{CDCl}_{3}$ of the crude products in the coupling reaction of $\mathrm{CS}_{2}$ and $\mathrm{PO}$ at $120^{\circ} \mathrm{C}$. 

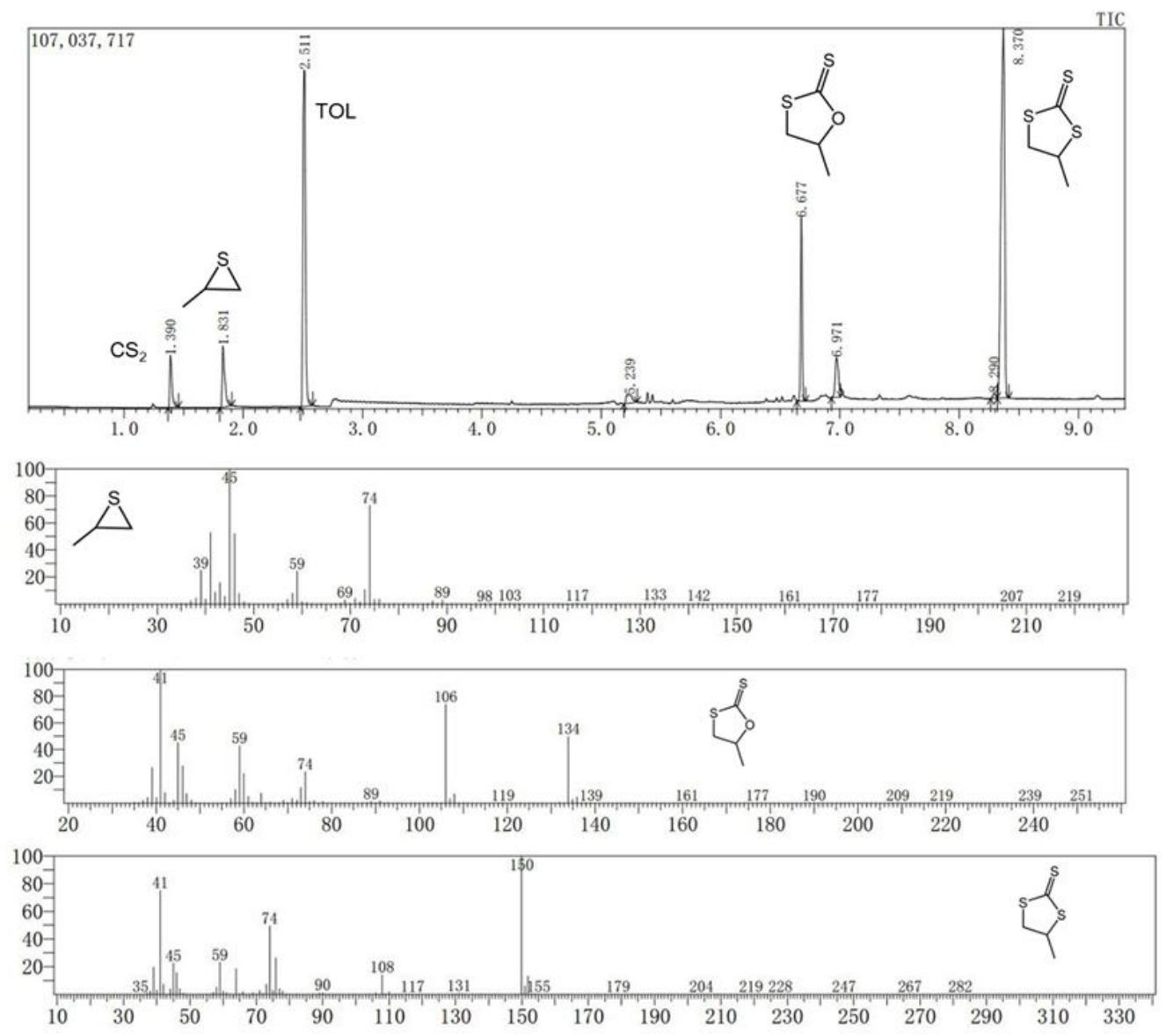

Fig. S15 GC-MS of the crude products in the coupling reaction of $\mathrm{CS}_{2}$ and PO at $120^{\circ} \mathrm{C}$. 


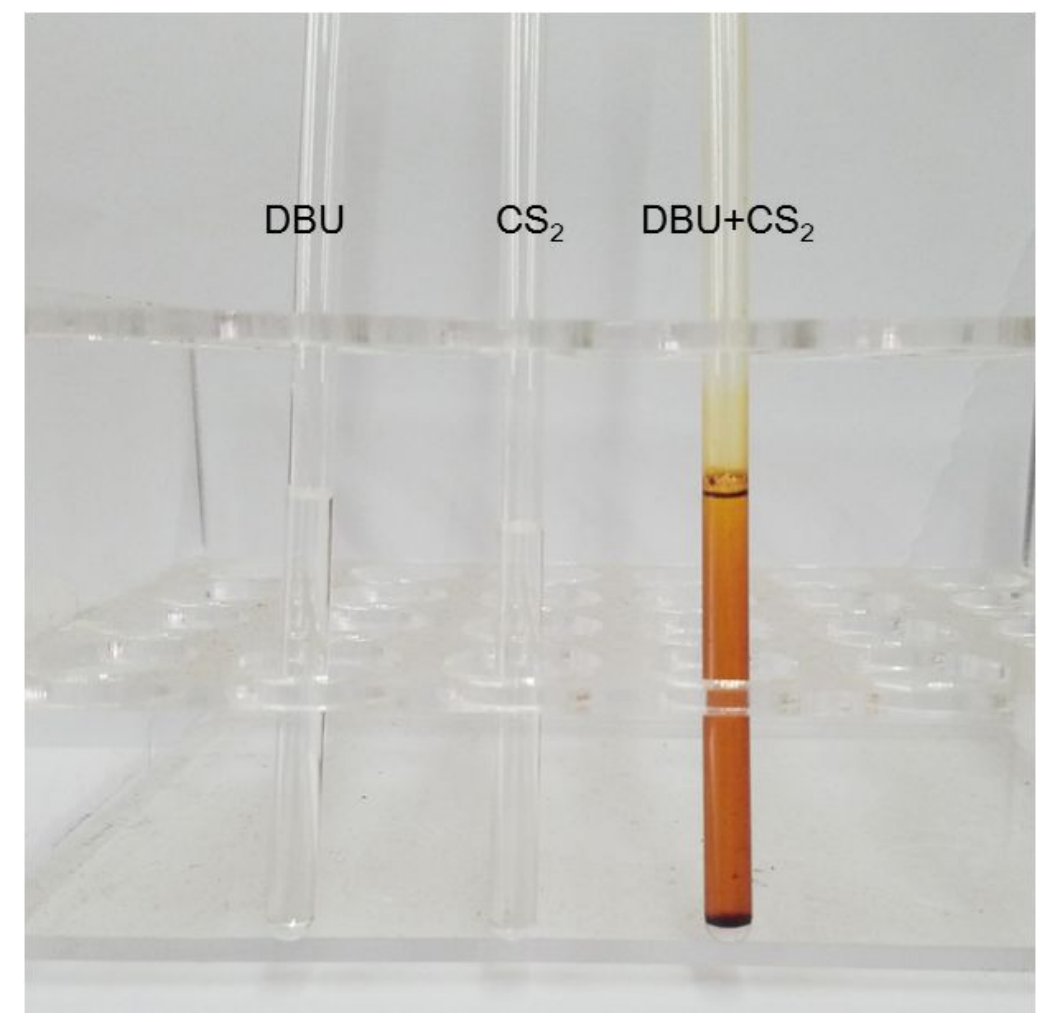

Fig. S16 The picture of DBU $(0.15 \mathrm{mmol}), \mathrm{CS}_{2}(0.15 \mathrm{mmol})$, and mixture of DBU $(0.15 \mathrm{mmol}) / \mathrm{CS}_{2}(0.15 \mathrm{mmol})$ (for $\left.10 \mathrm{~h}\right)$ in toluene $(0.5 \mathrm{ml})$ at 25 ${ }^{\circ} \mathrm{C}$. 


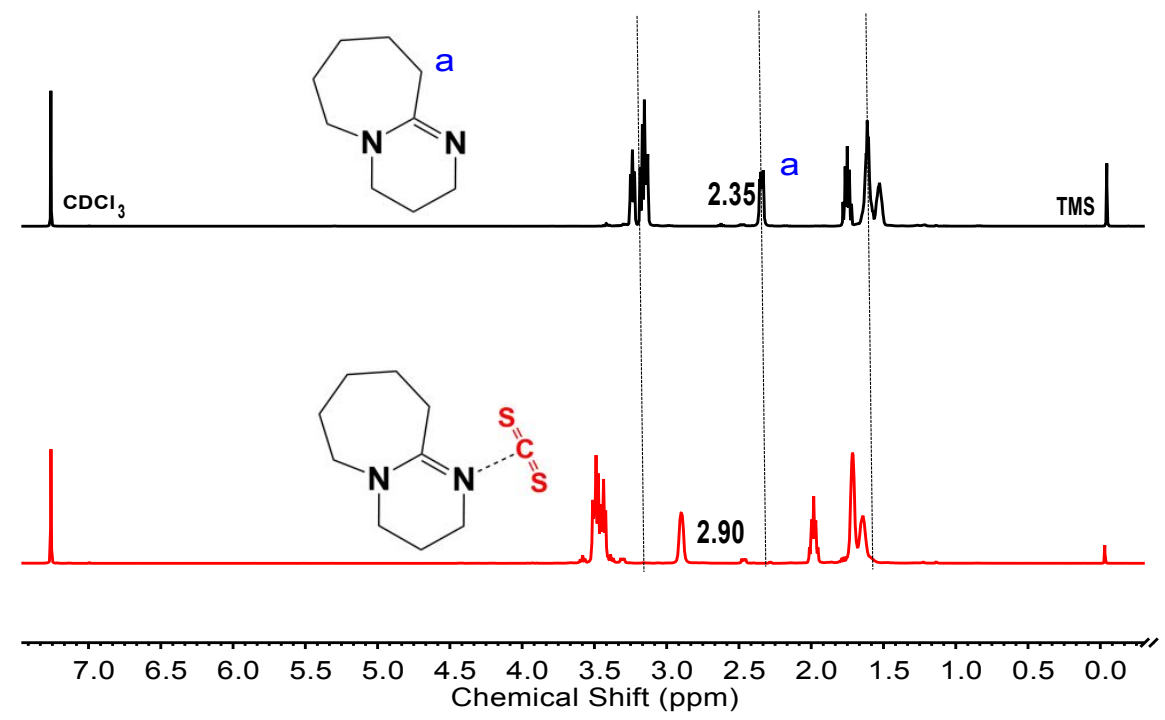

Fig. $\mathbf{S 1 7}{ }^{1} \mathrm{H}$ NMR spectra in $\mathrm{CDCl}_{3}$ of (a) DBU and (b) the precipitate in fig. S16. 


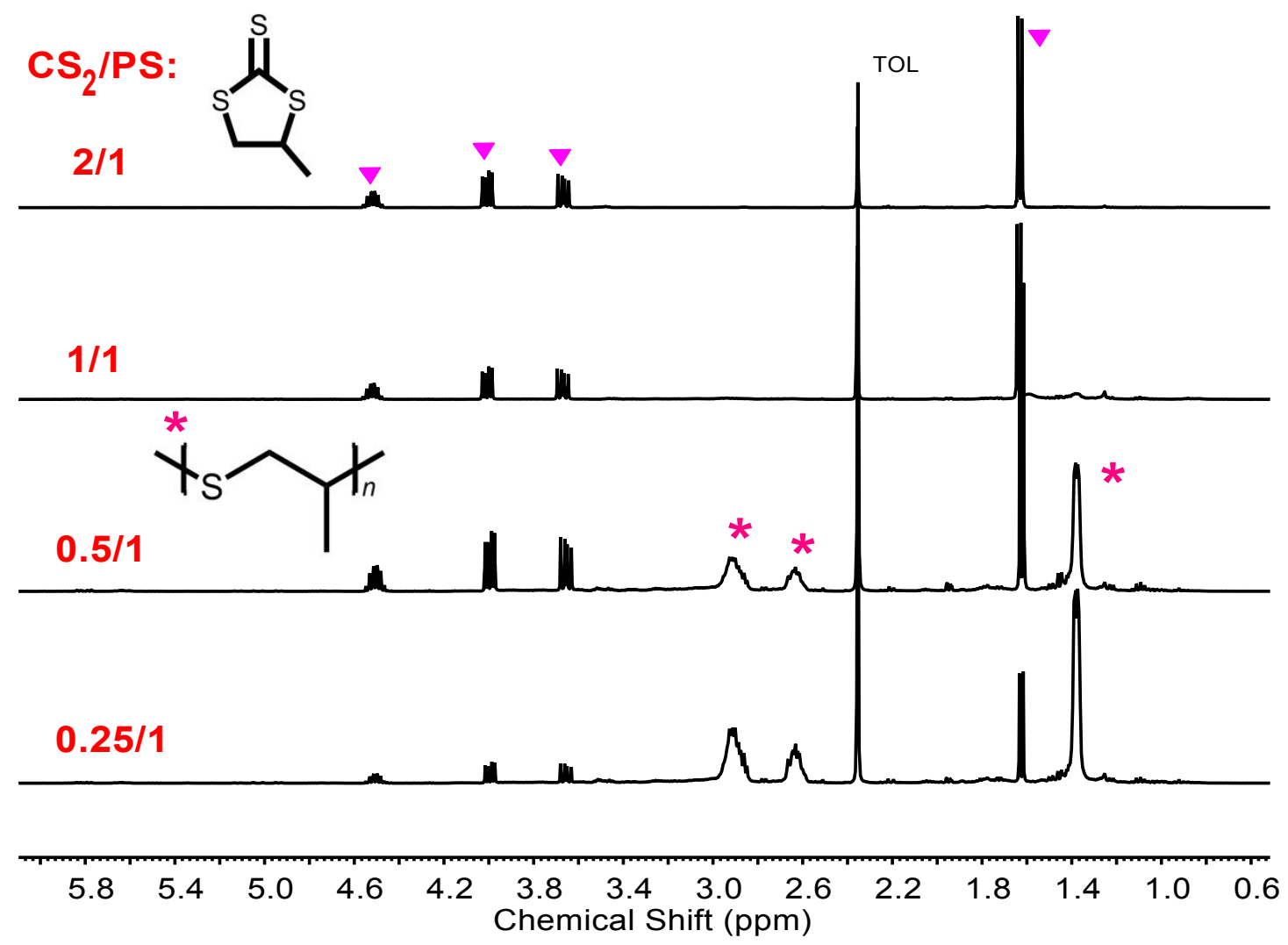

Fig. S18 ${ }^{1} \mathrm{H}$ NMR spectra in $\mathrm{CDCl}_{3}$ of the crude-products in table $\mathrm{S} 2$. 


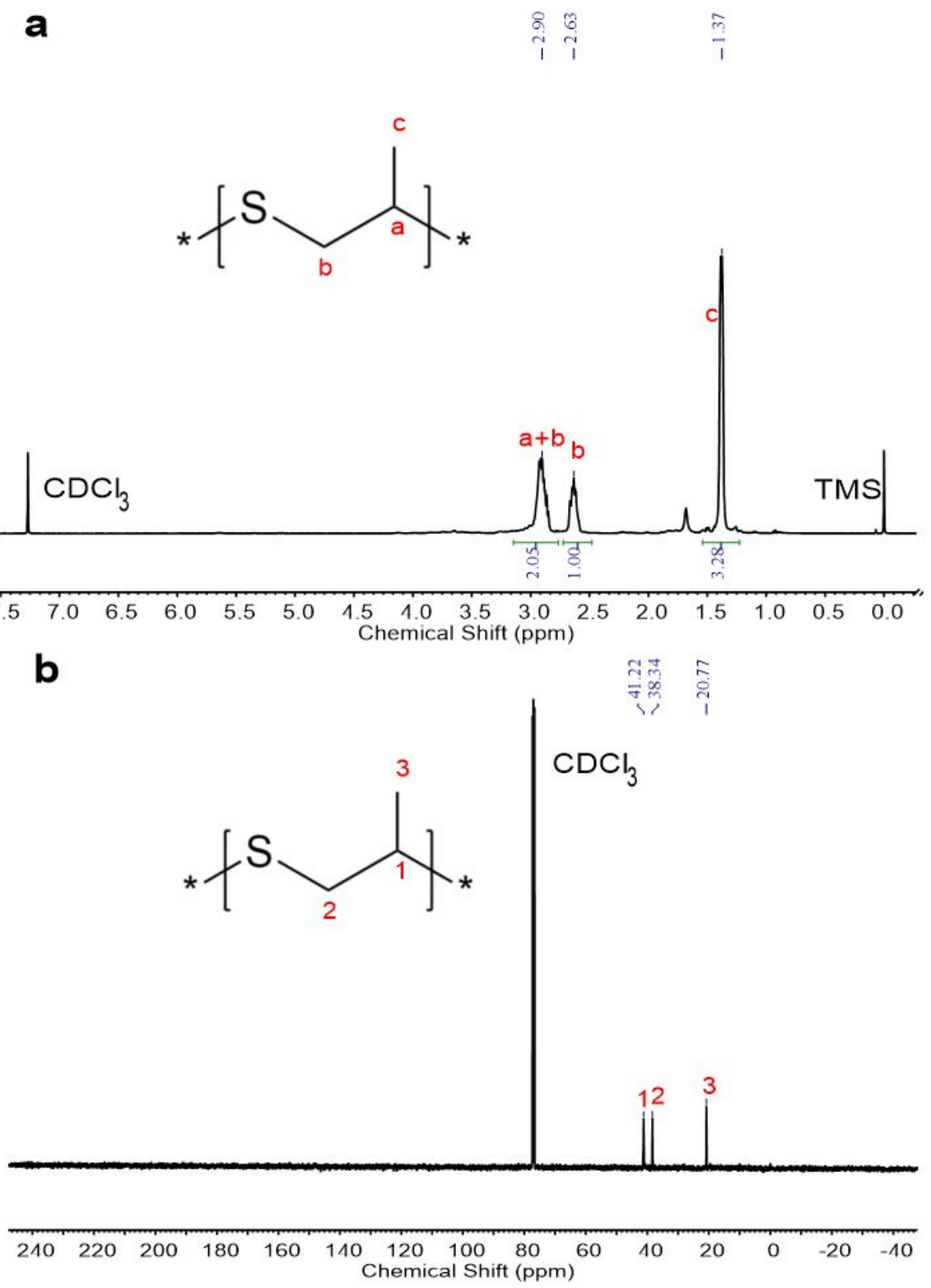

Fig. S19 (a) ${ }^{1} \mathrm{H}$ NMR and (b) ${ }^{13} \mathrm{C}$ NMR spectra in $\mathrm{CDCl}_{3}$ of the purified products in table S2, entry 3. 
a

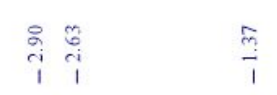<smiles>CC(CSC(C)(C)C)C(C)(C)C</smiles>
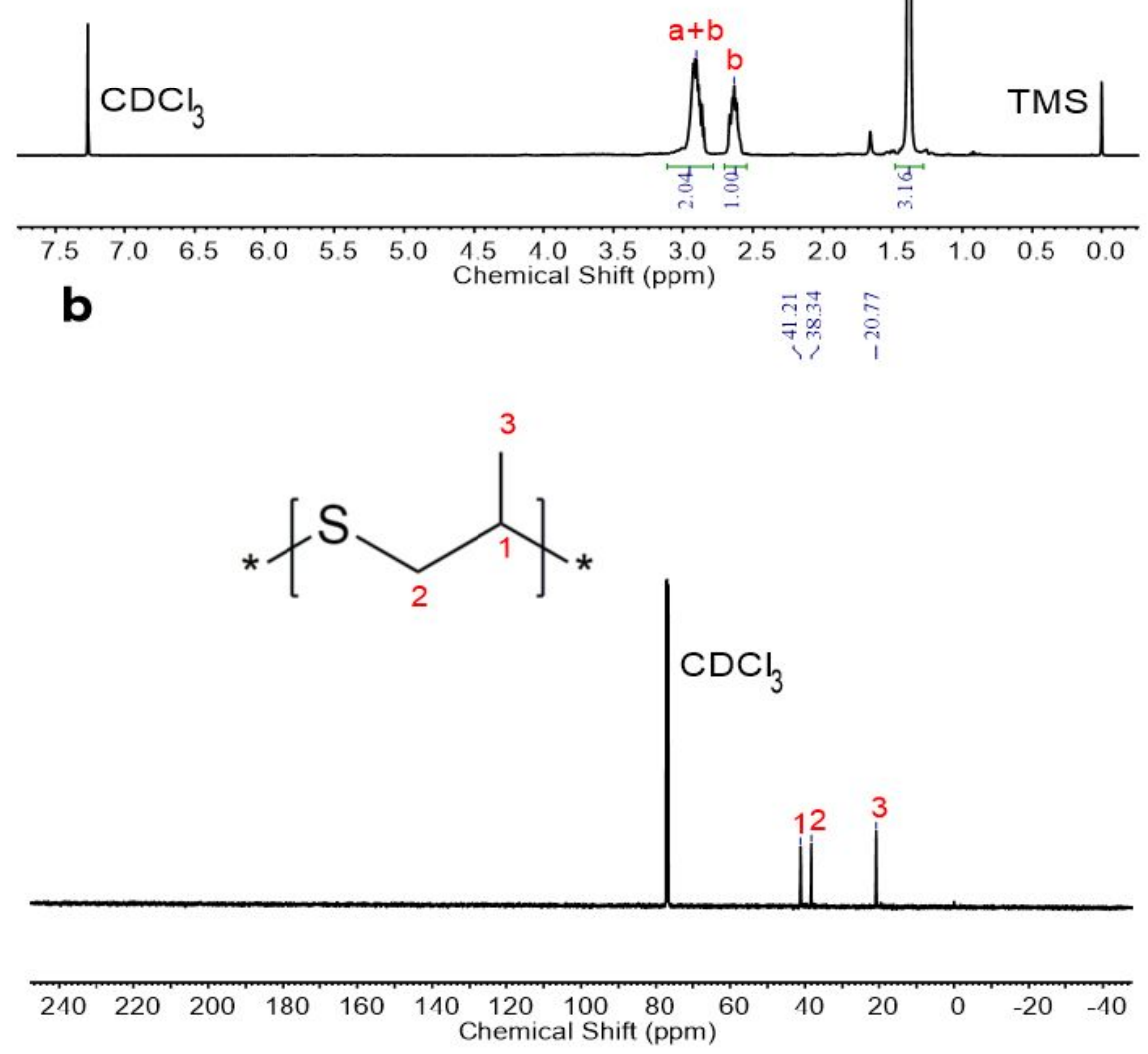

Fig. S20 (a) ${ }^{1} \mathrm{H}$ NMR and (b) ${ }^{13} \mathrm{C}$ NMR spectra in $\mathrm{CDCl}_{3}$ of the purified products in table S2, entry 4. 


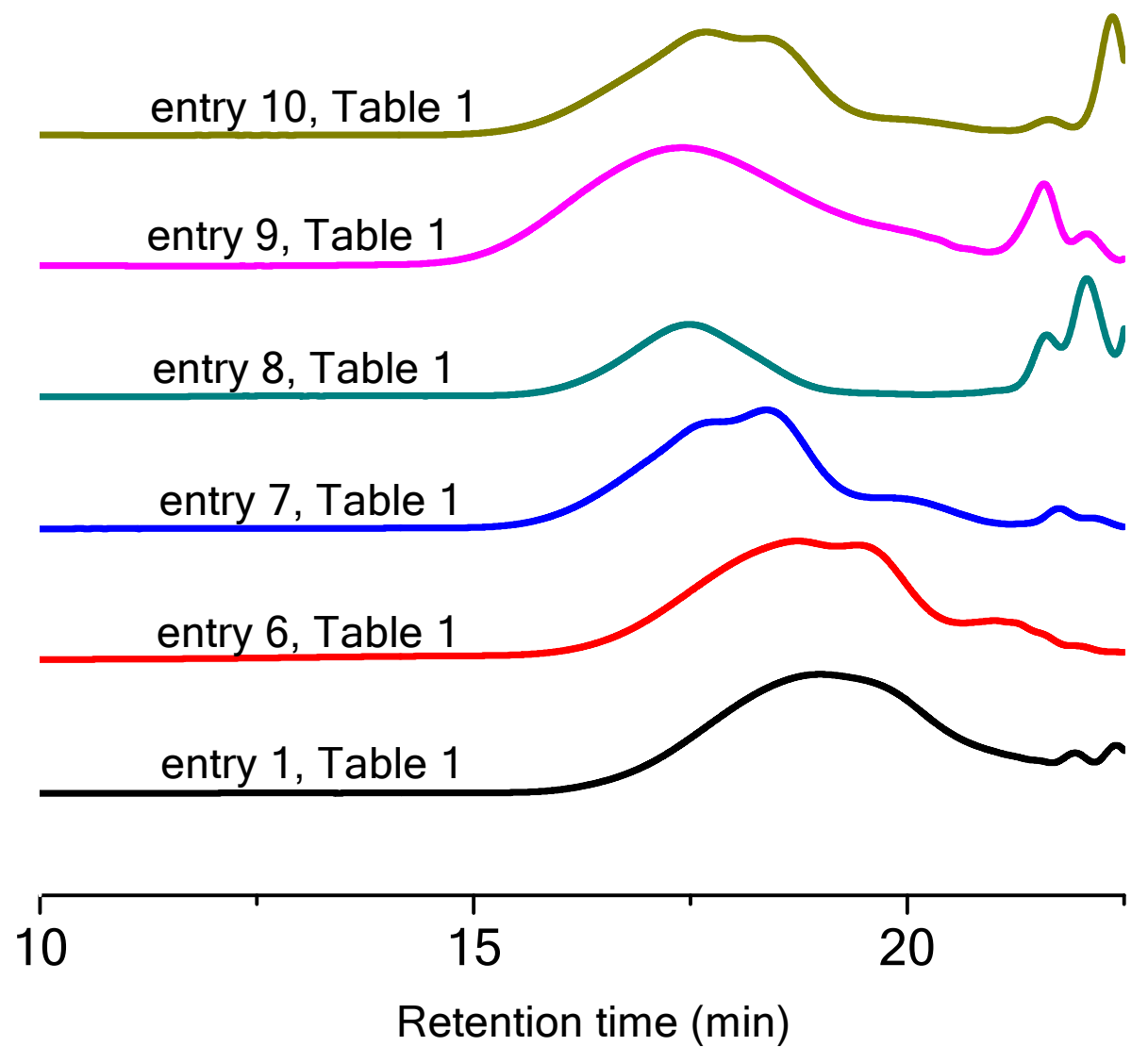

Fig. S21 GPC curves of the generated poly(thioether)s in entries 1, 6, 7, 8, 9 and 10 in Table 1. 
Table S1. Coupling reaction of $\mathrm{PO}$ with $\mathrm{CS}_{2}$ using DBU ${ }^{\text {[a] }}$

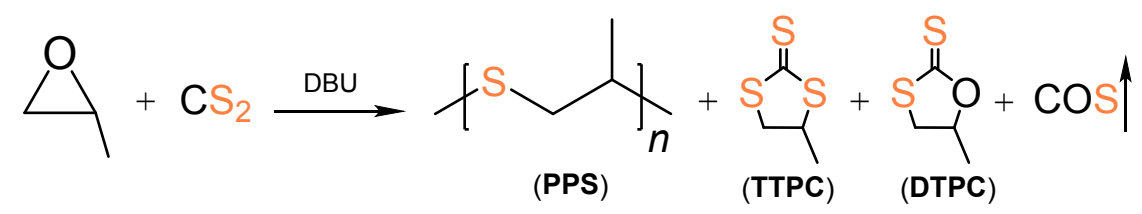

\begin{tabular}{lcccccc}
\hline Entry & Sol. & $\begin{array}{c}\text { Tem. } \\
\left({ }^{\circ} \mathrm{C}\right)\end{array}$ & $\begin{array}{c}\text { PPS:TTPC } \\
: D^{2} C^{[\mathrm{b}]}\end{array}$ & $\begin{array}{c}\text { Yield } \\
(\mathrm{g}, \%)^{[\mathrm{c}]}\end{array}$ & $\begin{array}{c}M_{\mathrm{n}} \\
(\mathrm{g} / \mathrm{mol})^{[\mathrm{d}]}\end{array}$ & $\begin{array}{c}Ð \\
\left(M_{\mathrm{w}} / M_{\mathrm{n}}\right)^{[\mathrm{d}]}\end{array}$ \\
\hline $1^{[\mathrm{e}]}$ & TOL & 120 & $78: 22: 0$ & $11.2(70)$ & 1900 & 1.5 \\
2 & TOL & 100 & $0: 43: 57$ & 0 & - & - \\
3 & TOL & 140 & $50: 50: 0$ & $2.1(40)$ & 1100 & 1.5 \\
$4^{[\mathrm{f}]}$ & DMF & 120 & $0: 0: 0$ & 0 & - & - \\
$5^{[\mathrm{f}]}$ & $\mathrm{DMAC}^{120}$ & $0: 0: 0$ & 0 & - & - \\
6 & $\mathrm{C}_{6} \mathrm{H}_{3} \mathrm{Cl}_{3}$ & 120 & $30: 70: 0$ & $1.1(21)$ & 1200 & 1.5 \\
\hline
\end{tabular}

[a] Reactions were run at $120{ }^{\circ} \mathrm{C}$ in $5.0 \mathrm{ml}$ solvent (PO: $5.0 \mathrm{ml}$; with the $\mathrm{PO} / \mathrm{CS}_{2} / \mathrm{DBU}$ molar ratio of $100 / 150 / 1$ ) in a $25 \mathrm{ml}$ flask with reflux device, $12 \mathrm{~h}$, PO was totally consumed determined by ${ }^{1} \mathrm{H}$ NMR spectroscopy.

[b] The molar ratio of poly(thioether)s to cyclic thiocarbonates in the final products, determined by ${ }^{1} \mathrm{H}$ NMR spectroscopy.

[c] Poly(thioether)s' yield, determined by gravimetry.

[d] Determined by gel permeation chromatography in THF, calibrated with polystyrene standards.

[e] $15 \mathrm{ml}$ PO with $15 \mathrm{ml}$ TOL in a $100 \mathrm{ml}$ flask.

[f] PO conversion of $0 \%$. 
Table S2. Coupling reaction of propylene sulfide with $\mathrm{CS}_{2}$ using DBU ${ }^{[\mathrm{a}]}$

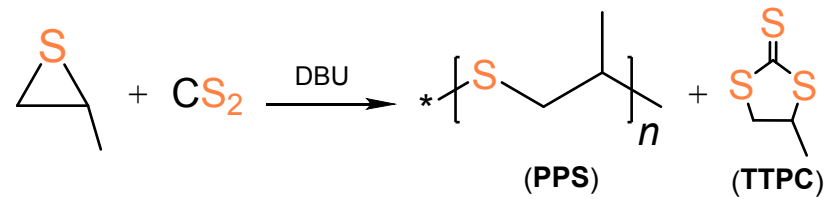

\begin{tabular}{lcccc}
\hline Entry & $\mathrm{CS}_{2}:$ PS $[\mathrm{b}]$ & $\begin{array}{c}\text { PPS:TTPC } \\
{[\mathrm{c}]}\end{array}$ & $\begin{array}{c}M_{\mathrm{n}} \\
(\mathrm{g} / \mathrm{mol})^{[\mathrm{d}]}\end{array}$ & $\begin{array}{c}Ð \\
\left(M_{\mathrm{w}} / M_{\mathrm{n}}\right)^{[\mathrm{d}]}\end{array}$ \\
\hline 1 & $2: 1$ & $0: 100$ & - & - \\
2 & $1: 1$ & $0: 100$ & - & - \\
3 & $0.5: 1$ & $70: 30$ & 2800 & 1.6 \\
4 & $0.25: 1$ & $90: 10$ & 2900 & 1.5 \\
\hline
\end{tabular}

[a] Reactions were run at $120^{\circ} \mathrm{C}$ in $0.3 \mathrm{ml}$ toluene (PS: $0.5 \mathrm{ml}$; with th PS/DBU molar ratio of 50/1) in a $25 \mathrm{ml}$ pressure tubing, $12 \mathrm{~h}$, propylene sulfide was totally consumed determined by ${ }^{1} \mathrm{H}$ NMR spectroscopy (fig. 4d).

[b] Molar ratio.

[c] The molar ratio of PPS to TTPC in the final products, determined by ${ }^{1} \mathrm{H}$ NMR spectroscopy (fig. 4d).

[d] Determined by gel permeation chromatography in THF, calibrated with polystyrene standards. 